\title{
A Scoping Review of Current Guidelines on Dietary Fat and Fat Quality
}

\author{
Lukas Schwingshackl ${ }^{\mathrm{a}} \quad$ Jasmin Zähringer ${ }^{\mathrm{a}} \quad$ Jessica Beyerbach ${ }^{\mathrm{a}}$ \\ Sarah S. Werner ${ }^{a}$ Blin Nagavci ${ }^{a}$ Helmut Heseker ${ }^{b}$ Berthold Koletzko ${ }^{c}$ \\ Joerg J. Meerpohl ${ }^{a, d}$ on behalf of the International Union of Nutritional \\ Sciences (IUNS) Task force on Dietary Fat Quality \\ anstitute for Evidence in Medicine, Medical Center-University of Freiburg, Faculty of Medicine, University of

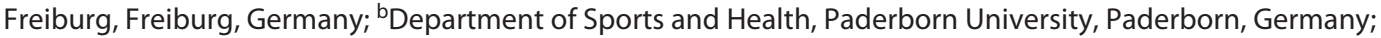 \\ 'Division of Metabolic and Nutritional Medicine, Department of Paediatrics, Dr. von Hauner Children's Hospital, \\ LMU - Ludwig-Maximilians-Universität Munich, University of Munich Medical Center, Dr. von Hauner Children's

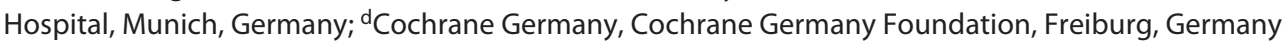

\section{Keywords}

Scoping review $\cdot$ Dietary fat $\cdot$ Dietary guidelines $\cdot$ Fat quality $\cdot$ Recommendations

\begin{abstract}
Introduction: We conducted a scoping review of dietary guidelines with the intent of developing a position paper by the "IUNS Task force on Dietary Fat Quality" tasked to summarize the available evidence and provide the basis for dietary recommendations. Methods: We systematically searched several databases and Web sites for relevant documents published between 2015 and 2019. Results: Twenty documents were included. Quantitative range intake recommendations for daily total fat intake included boundaries from 20 to $35 \%$ of total energy intake (TEI), for monounsaturated fat (MUFA) $10-25 \%$, for polyunsaturated fat (PUFA) $6-11 \%$, for saturated-fat (SFA) $\leq 11-\leq 7 \%$, for industrial transfat (TFA) $\leq 2-0 \%$, and $<300-<200 \mathrm{mg} / \mathrm{d}$ for dietary cholesterol. The methodological approaches to grade the strength of recommendations were heterogeneous, and varied highly between the included guidelines. Only the World Health
\end{abstract}

Organization applied the GRADE approach and graded the following recommendation as "strong": to reduce SFA to below $10 \%$, and TFA to below $1 \%$ and replace both with PUFA if SFA intake is greater than $10 \%$ of TEl. Conclusion: Although the methodological approaches of the dietary guidelines were heterogeneous, most of them recommend total fat intakes of $30-\leq 35 \%$ of TEl, replacement of SFA with PUFA and MUFA, and avoidance of industrial TFA.

(c) 2021 S. Karger AG, Basel

\section{Introduction}

In the past decades, dietary guidance mainly focused on reducing the intake of total fat, saturated fat (SFA), and dietary cholesterol. This guidance was mostly driven by the "diet-heart hypothesis" postulated by Ancel Keys nearly 70 years ago [1]. This hypothesis was based on the observation that a high fat diet increases serum cholesterol and that elevated serum cholesterol levels in turn are associated with coronary heart disease (CHD) $[1,2]$. More recently this emphasis shifted from limiting total 
dietary fat intake to the replacement of SFA with unsaturated fats and the avoidance of industrial trans-fats (TFA) [3]. For example, in 1980, the Dietary Guidelines for Americans (DGA) recommended limiting dietary fat to $<30 \%$ of total energy intake (TEI) [4]. The 2000 DGA modified the 1995 guideline from "Choose a Diet Low in Fat, Saturated Fat and Cholesterol" to "Choose a diet that is low in saturated fat and cholesterol and moderate in total fat" to shift the emphasis from total fat to type of fat [5]. This recommendation was revised in 2005, including a range from 20 to $35 \%$ of TEI [6]. In the DGA 2015-2020, the recommendation to limit intake of calories from SFA to $<10 \%$ per day was based on evidence that replacing SFA with unsaturated fats is associated with decreased risk of cardiovascular disease (CVD), with no recommendation for TEI [3]. Furthermore, in the 2015-2020 edition of the DGA, an earlier recommendation to limit the consumption of dietary cholesterol to $300 \mathrm{mg} / \mathrm{d}$ was withdrawn due to, on the basis of contemporary intake levels, it was no longer a nutrient of public health concern [3]. However, the DGA have also been criticized for failing to take into account all available relevant scientific evidence (by omitting e.g., available evidence on SFA) [7].

Worldwide, noncommunicable diseases such as CVD, cancer, and type 2 diabetes (T2D) account for over $70 \%$ of total deaths [8]. Diet itself has long been recognized to be a key determinant of health, and according to the Global Burden of Disease study, a suboptimal diet is the leading risk factor for $\sim 50 \%$ of disabilities from CVDs [9]. Evidence based dietary recommendations are of major importance for the prevention of chronic diseases, however, the role of dietary fat is being discussed controversially.

The scope of this review is to identify, describe, and summarize comprehensively all governmental dietary guidelines, and dietary guidelines by health related organizations and associations on fat intake and fat quality. Our scoping review on dietary guidelines will serve as a basis for a position paper by the "International Union of Nutritional Sciences Task force on Dietary Fat Quality" that was tasked to summarize the available evidence and provide dietary recommendations.

\section{Methods}

We conducted this scoping review according to the methodology of the Joanna Briggs Institute's Reviewers' Manual [10]. For reporting, we followed the Preferred Reporting Items for Systematic reviews and Meta-Analyses extension for scoping reviews, the Preferred Reporting Items for Systematic reviews and Meta-Analyses-ScR Statement [11].

\section{Search Strategy}

The databases Medline (via Ovid), the Cochrane Library, and Epistemonikos were searched for relevant articles published from January 1, 2015 to December 31, 2019 (search conducted: February 19,2020 ), with no restriction by language. Furthermore, an extensive search through the Google ${ }^{\mathrm{TM}}$ search engine was performed. In addition, the Guidelines International Network, the Training Research Into practice, and Guideline Central databases were also screened for relevant guidelines. Guidelines and recommendations by the Food and Agriculture Organization of the United Nations, the World Health Organization (WHO), World Cancer Research Fund International, the Center for Disease Control, and the American Heart Association were searched as well. The Medline (Ovid), Cochrane Library, and Epistemonikos search strategy is presented in the see online suppl. Appendix 1; for all online suppl. material, see www.karger.com/doi/10.1159/000515671.

\section{Selection of Documents}

Inclusion Criteria

Documents fulfilling the following criteria were included in the scoping review: (i) Governmental dietary guidelines, and guidelines by health related organizations and associations on fat intake and fat quality. (ii) Guidelines on adult ( $\geq 18$ years of age) human beings published in the last 5 years (January 01, 2015-December 31,2019). (iii) Guidelines focusing on interventions of or exposure to dietary fat (total fat) and/or fat quality (SFA, monounsaturated fat (MUFA), polyunsaturated fat (PUFA), TFA, omega-6 (linoleic acid [LA]), omega-3 fatty acids (FA), including, eicosapentaenoic acid, docosahexaenoic acid, $\alpha$-linolenic acid (ALA); and dietary cholesterol). (iv) Guidelines addressing prevention of chronic disease outcomes, such as CVD, including CHD and stroke; cancer; T2D; hypertension; obesity; or guidelines for the general population to give recommendations for adequate nutrient supply, and (v) guidelines with at least 1 quantitative recommendation for any of the followings: total fat, MUFA, PUFA, SFA, TFA, omega-3, or omega-6 FA.

\section{Exclusion Criteria}

Guidelines that met any of the following criteria were excluded: (i) Inclusion of solely critically ill and hospitalized patients; or patients undergoing bariatric surgery; or patients with eating disorders. (ii) Inclusion of solely infants, children and adolescents; pregnant and lactating women; and elderly. (iii) Guidelines based on dietary supplements only; and (iv) documents (including foodbased dietary guidelines) that had no quantitative recommendations for any of the followings: total fat, MUFA, PUFA, SFA, TFA, omega-3, or omega-6 FA.

\section{Selection Process of Sources of Evidence}

First, title and abstract screening was performed by 1 reviewer (J.Z.). Only clearly irrelevant references were excluded at this stage. Second, for all potentially relevant references full-text publications were obtained and checked for final inclusion by 2 reviewers (J.Z., L.S.) independently. Uncertainties were resolved through discussion with a third author (J.J.M.).

\section{Data Extraction}

For included documents, 2 reviewers (J.Z. and J.B.) extracted the guideline characteristics, and another reviewer cross-checked all data (J.Z., J.B., and L.S.). The following data were extracted:
Schwingshackl et al. 
Fig. 1. Flow diagram showing study selec-

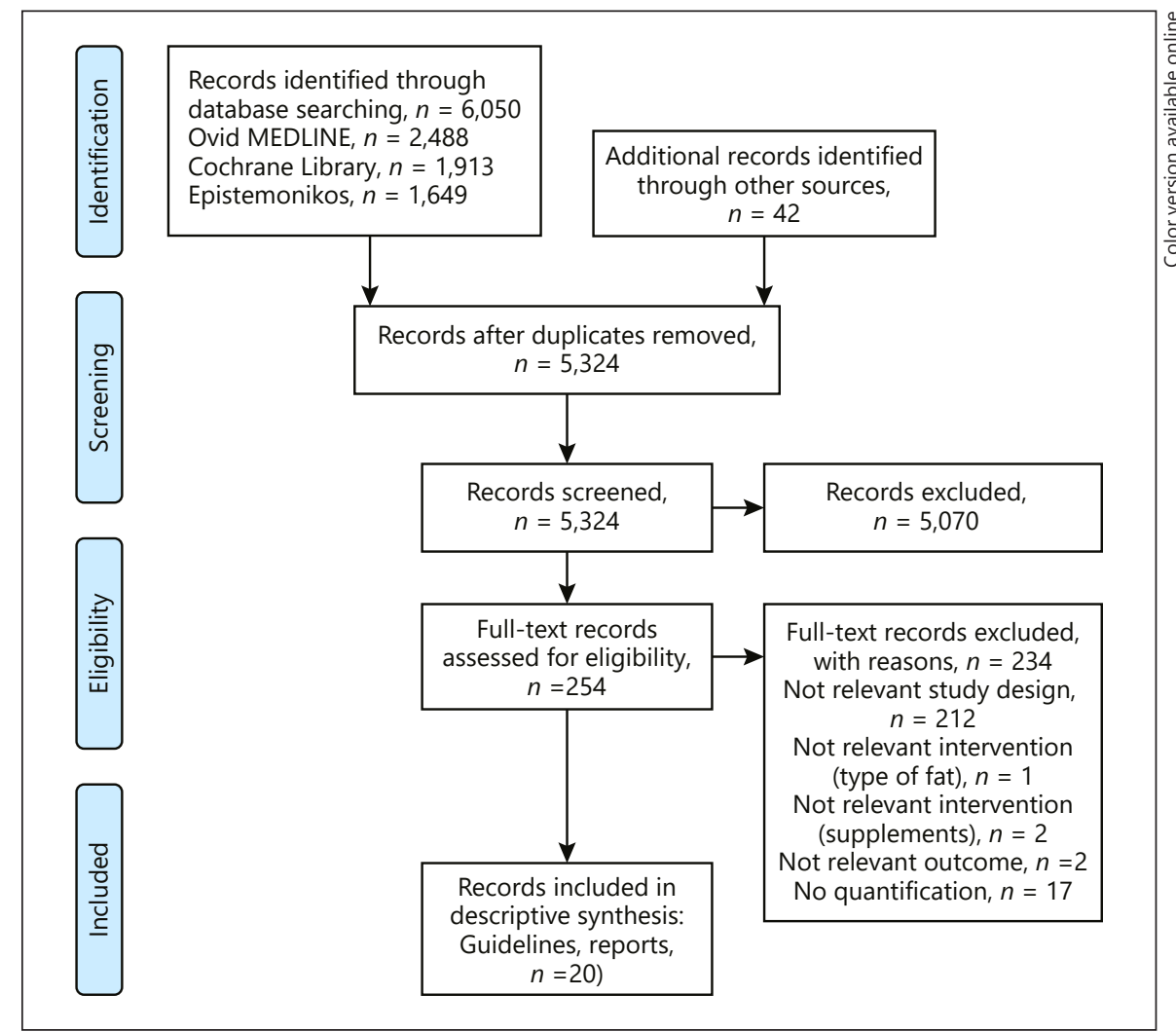
tion process.

guideline organization, year of publication, country, aim of guideline, target population, type of studies included, guideline methodology (systematic search for relevant studies, multidisciplinary panel, reporting conflict of interest of panel members), recommendations for dietary fat intake (e.g., total fat, SFA, and MUFA), type of grading/strength of recommendation. We also extracted nonquantitative recommendations, such as "replace SFA with PUFA and MUFA," if a guideline reported at least 1 quantitative recommendation for another type of fat; however, only quantitative recommendations are represented graphically.

\section{Results}

Of 5,324 records identified by the literature searches, 254 records were assessed as full texts (Fig. 1 and online suppl. Appendix 2). Finally, 20 guidelines on dietary fat and fat quality published in the last 5 years were included in the scoping review [3, 12-30] (Table 1).

The included guidelines were published by governmental bodies or subordinated departments $(n=12)$, or international/national professional societies or organizations $(n=8)$. These include national dietary guidelines and clinical practice guidelines, often with a focus on the general population and primary prevention, but also a few focusing on the management of metabolic disorders. The types of studies included in the corresponding guidelines varied, from systematic reviews (SRs) of randomized controlled trials (RCTs) and/or observational studies (including prospective cohort, case-control, cross-sectional), to individual RCTs and observational studies, as well as monographs, case reports/studies, qualitative research, guidelines from other countries, reports from other organizations, modeling studies, and mechanistic studies.

Three guidelines were published in the USA $[3,13$, $22]$, followed by 3 from the UK $[20,21,29]$. Three guidelines were issued by international professional societies/ organizations [19, 26, 27], 2 in Spain [14, 23], and 1 guideline each in Germany [15], Ecuador [25], Canada [30], Colombia [18], Italy [28], Argentina [16], New Zealand [17], Kenya [24], and Japan [12]. Eleven of 20 guidelines (55\%) conducted a systematic search for relevant studies [3, 12, 14-16, 18, 21, 23, 25, 26, 29], 15 of 20 (75\%) consisted of a multidisciplinary panel $[3,12-14,16-19$, $21,23,25-29]$, and 7 of 20 (35\%) reported statements regarding conflict of interest of panel members $[13,14,16$, 19, 22, 23, 27]. Table 1 shows the general and Table 2 the specific characteristics of the included guidelines sepa- 


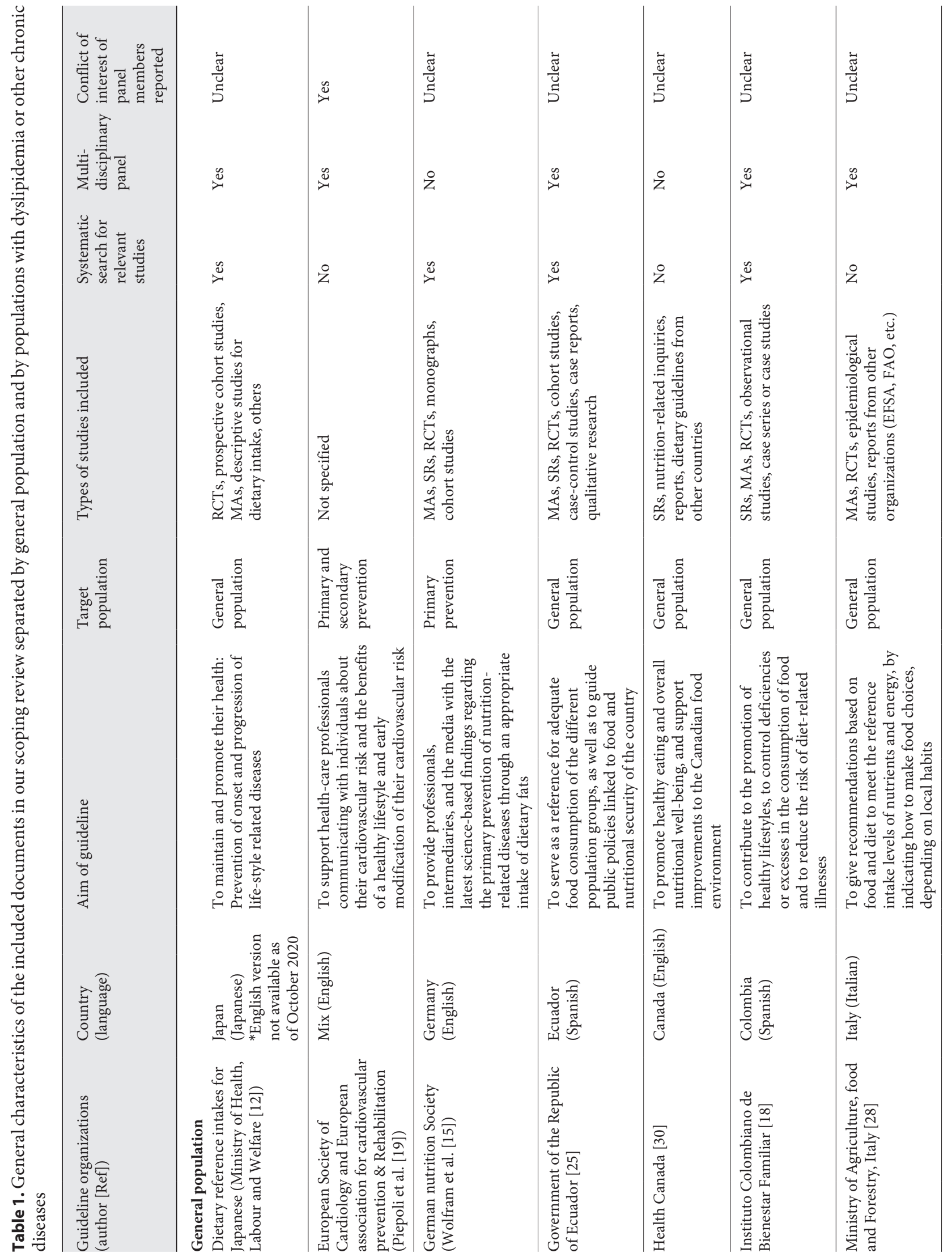




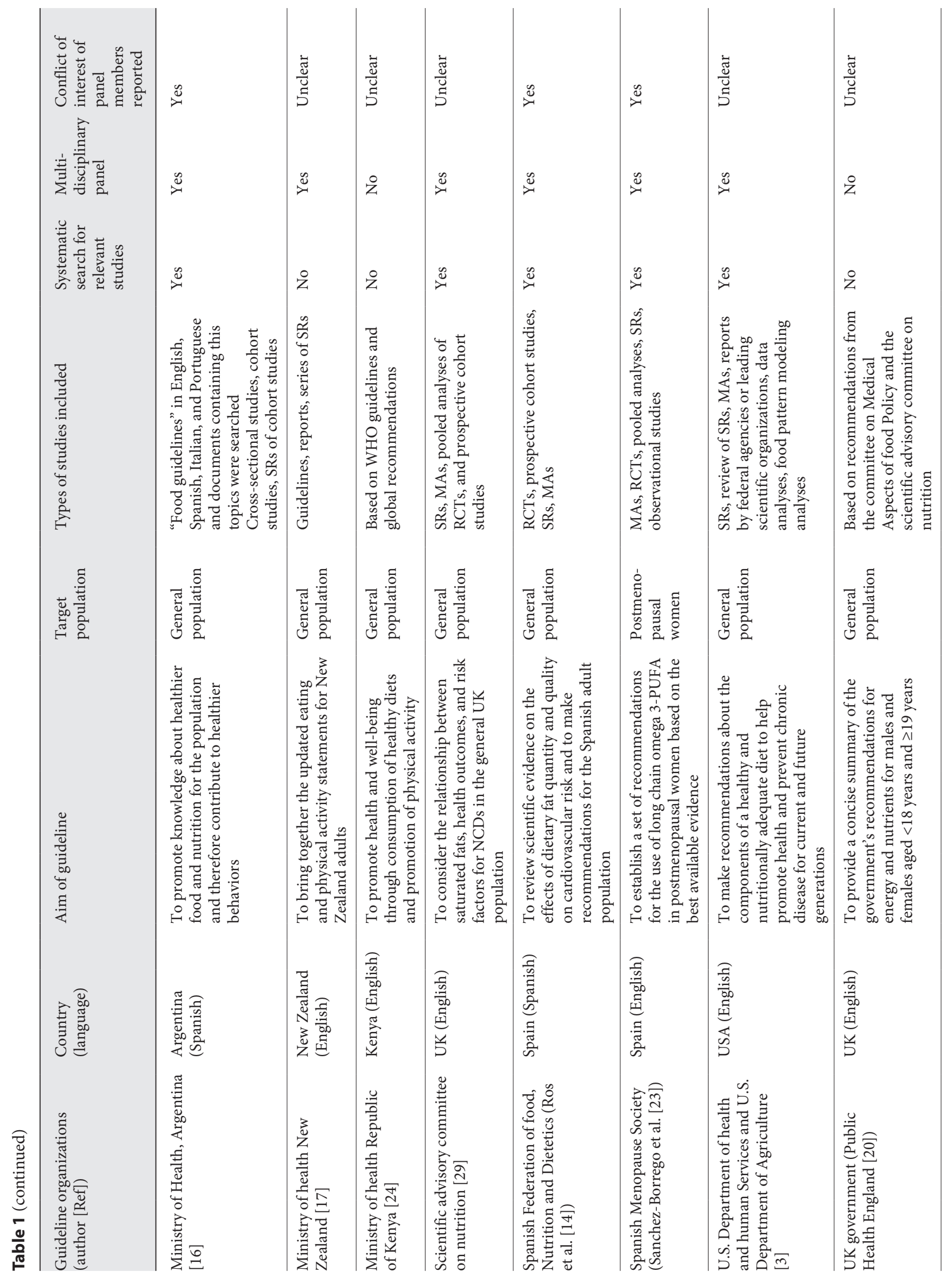




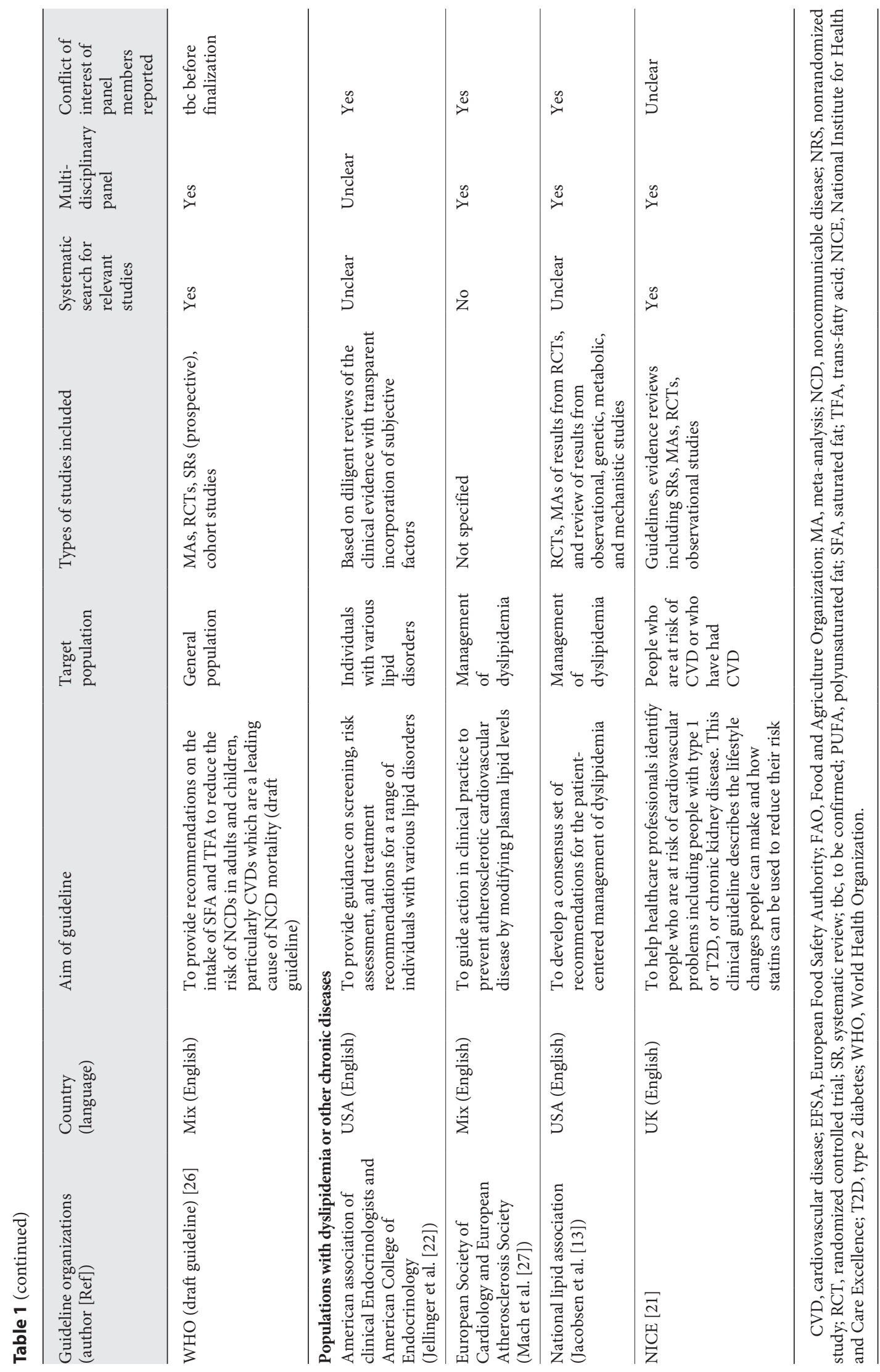



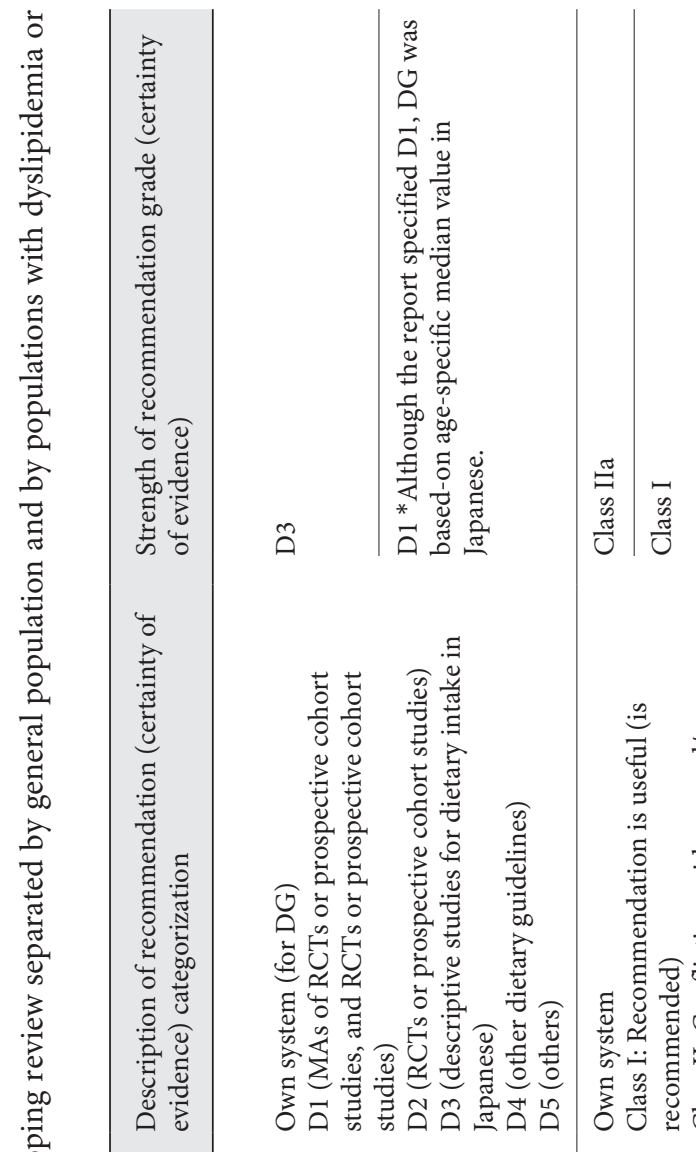

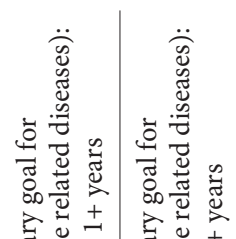

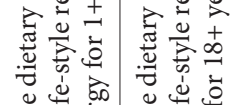

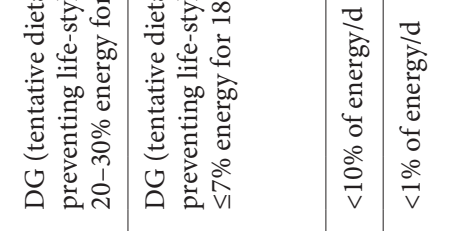

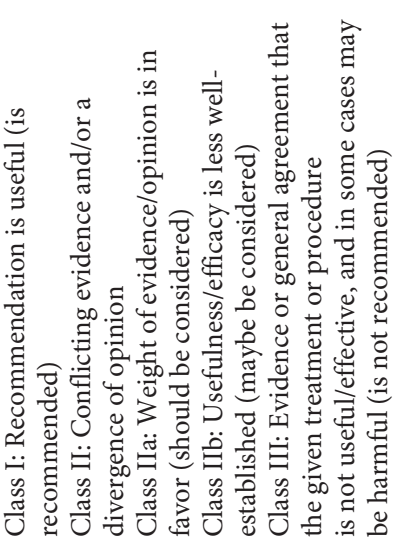

$\overleftrightarrow{z}$

$\overleftrightarrow{z}$

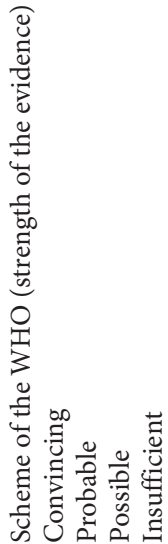

ప

寻

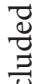

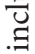

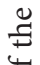

.्ֶ.

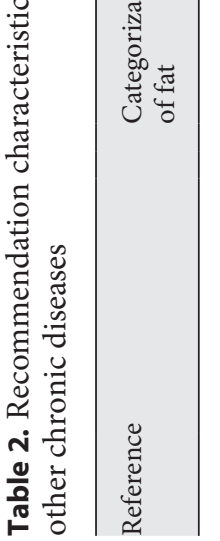

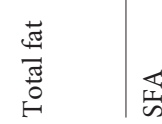

屈屋

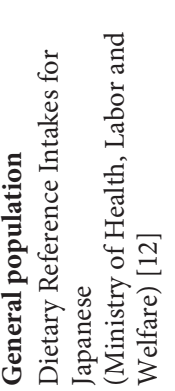

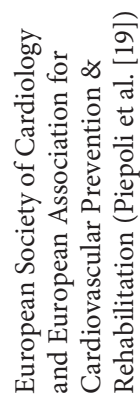

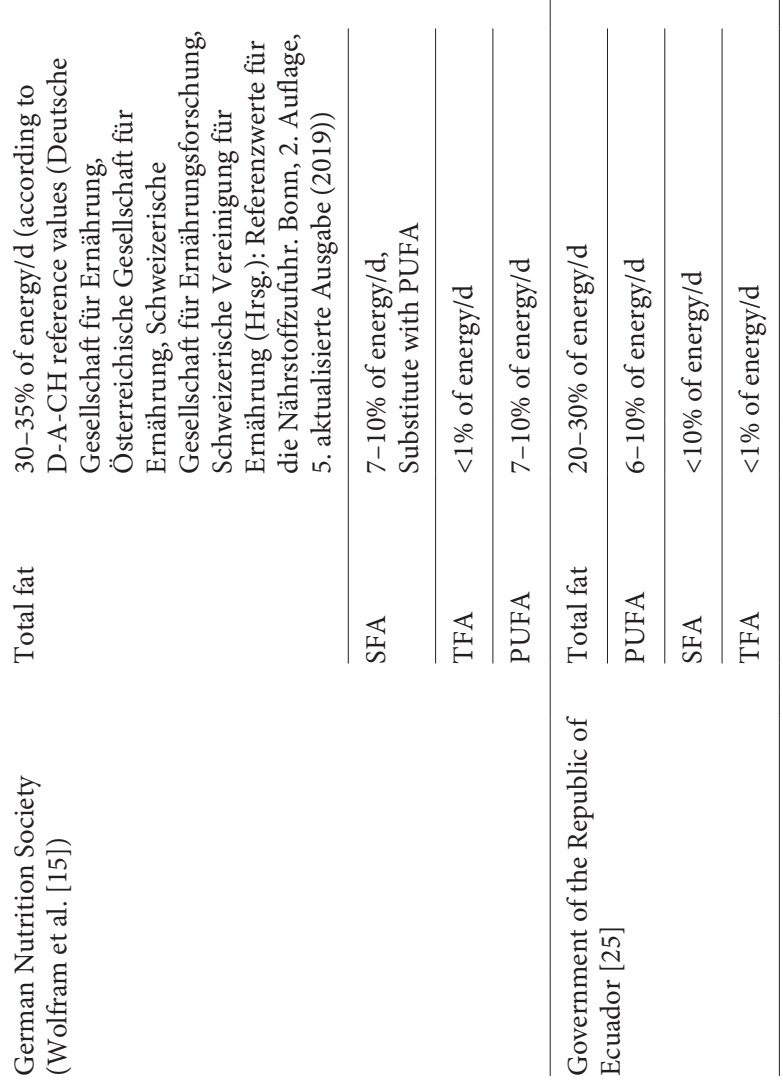




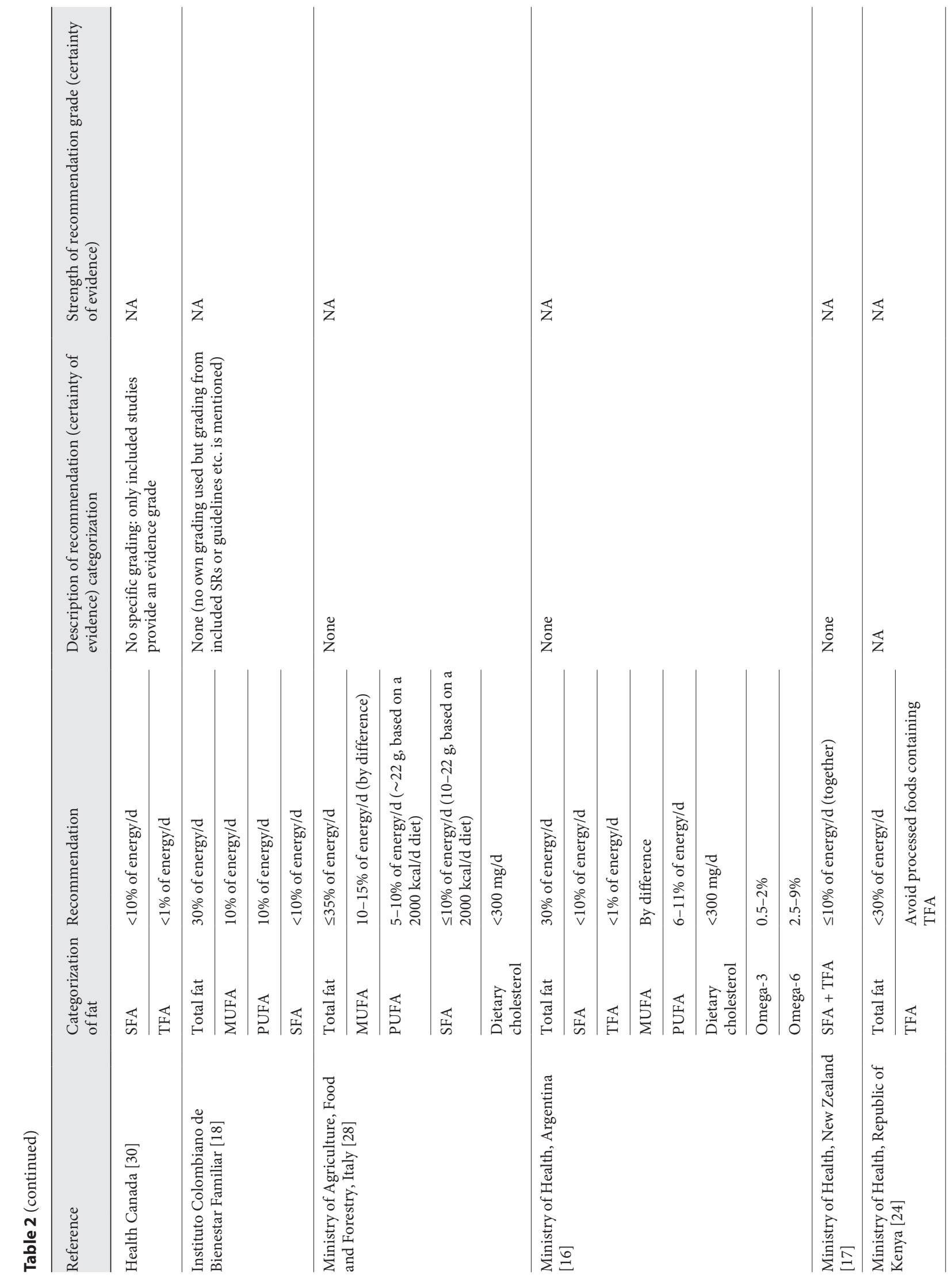




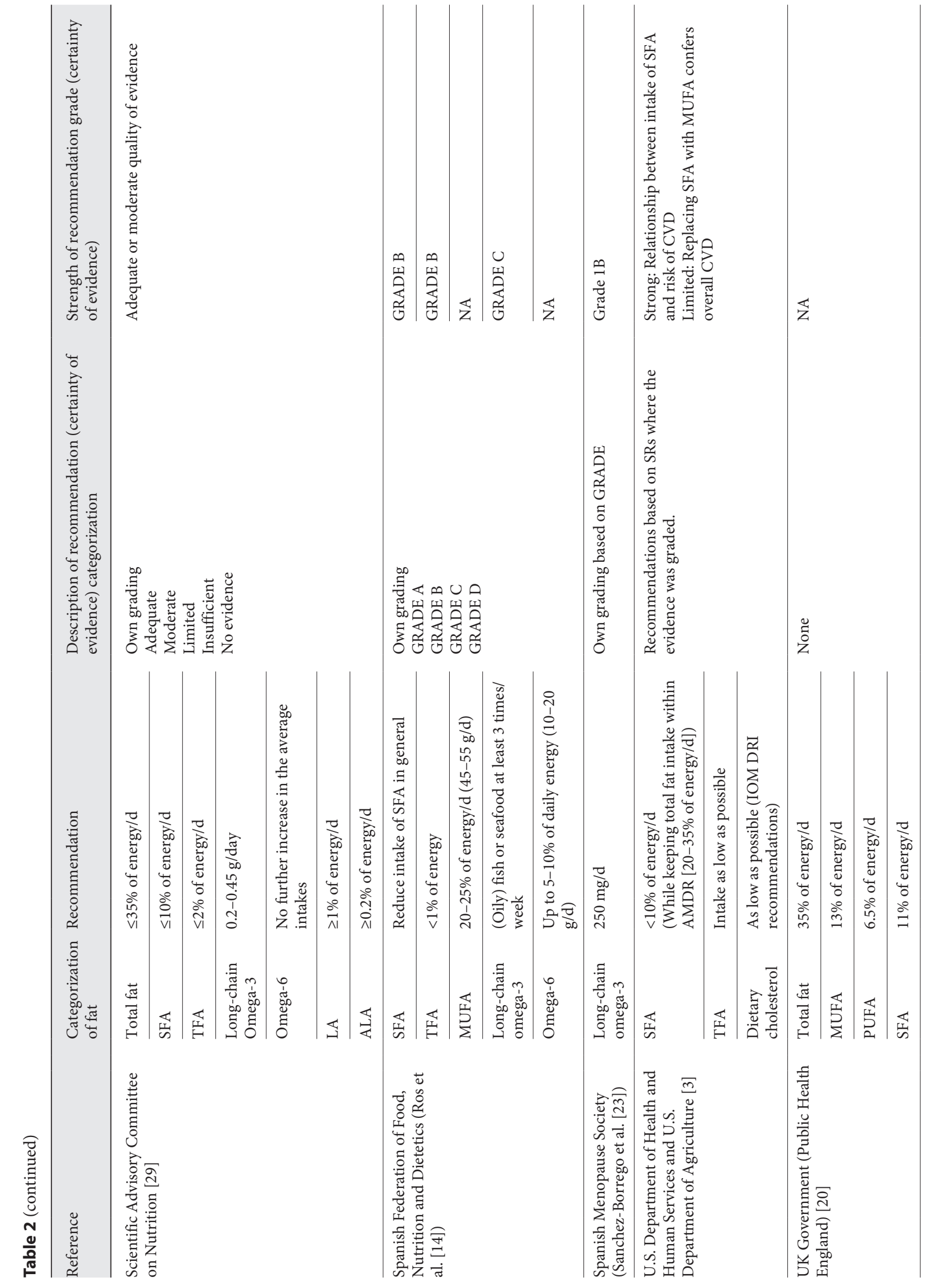




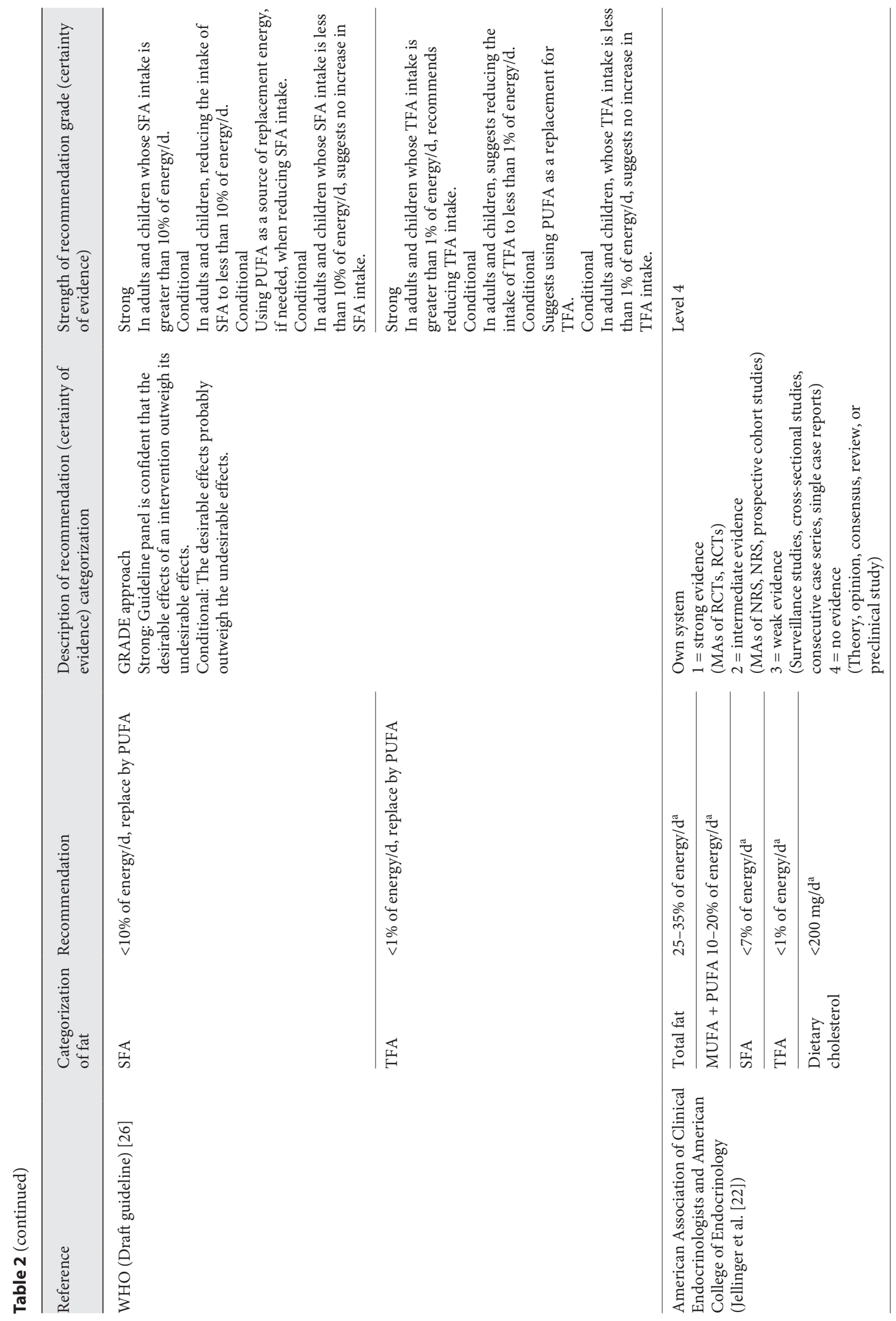




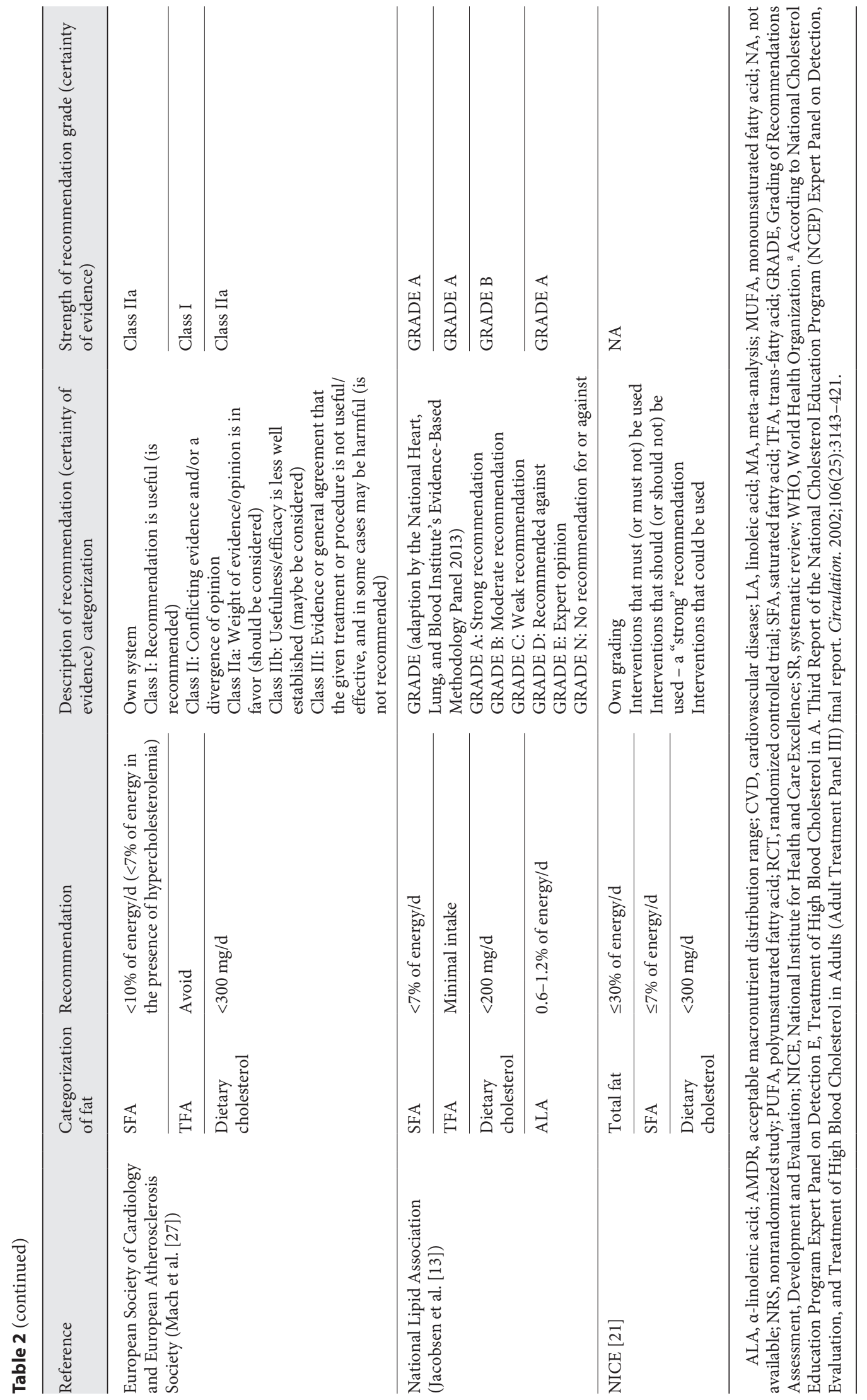




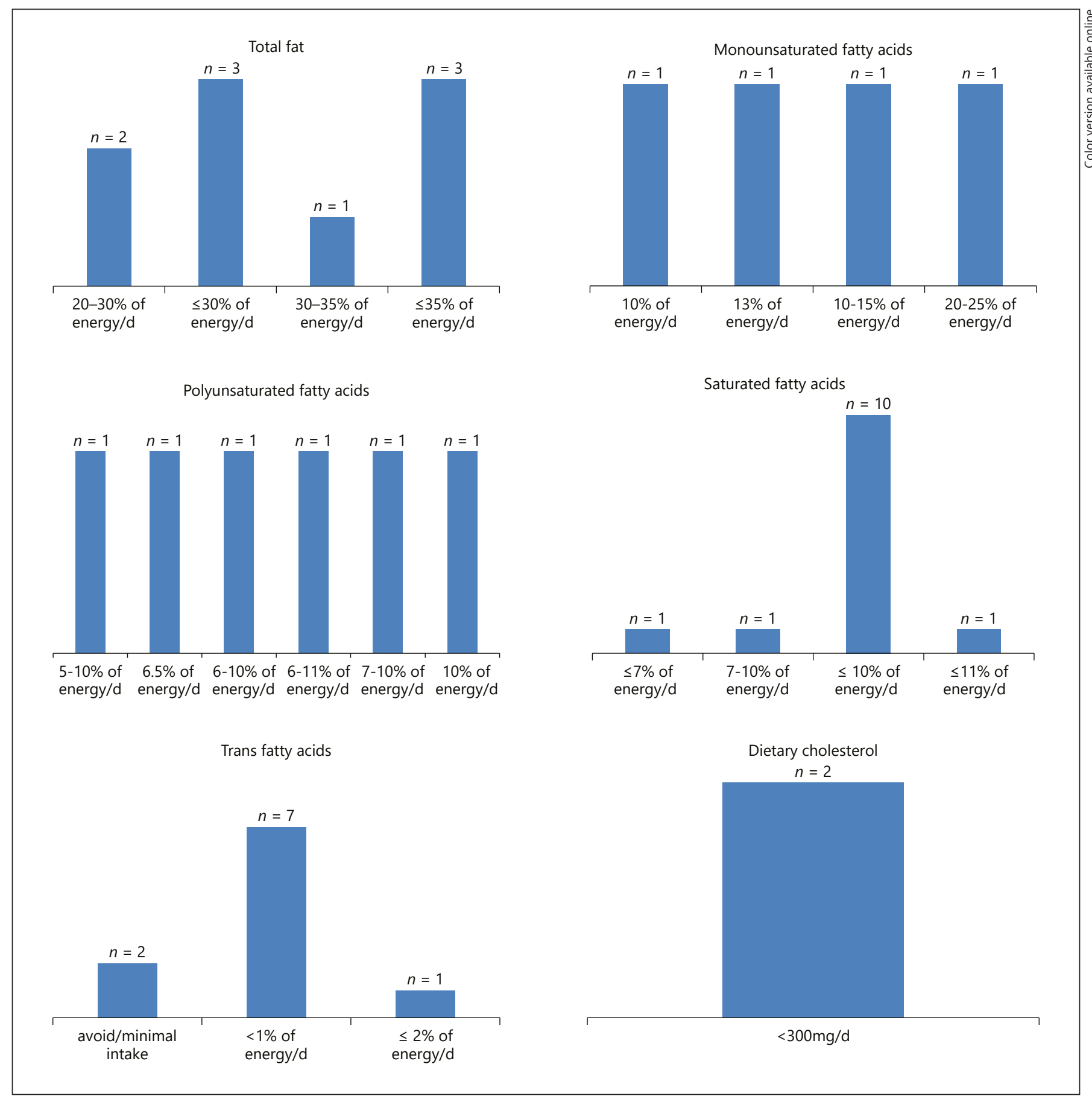

Fig. 2. Distributions of quantitative recommendations for total dietary fat intake and different types of fat of the included guidelines for the general population. SFA, saturated fatty acid; TFA, trans-fatty acid; PUFA, polyunsaturated fatty acid; MUFA, monounsaturated fatty acid.

rated by general population and by populations with dyslipidemia or other chronic diseases. Quantitative recommendation of total fat, MUFA, PUFA, SFA, TFA, and dietary cholesterol intake are shown in Figure 2 for the general population and in Figure 3 for patients with dyslipidemia. 
Fig. 3. Distributions of quantitative recommendations for total dietary fat intake and different types of fat of the included guidelines for the populations with dyslipidemia or other chronic diseases. SFA, saturated fatty acid; TFA, trans-fatty acid.

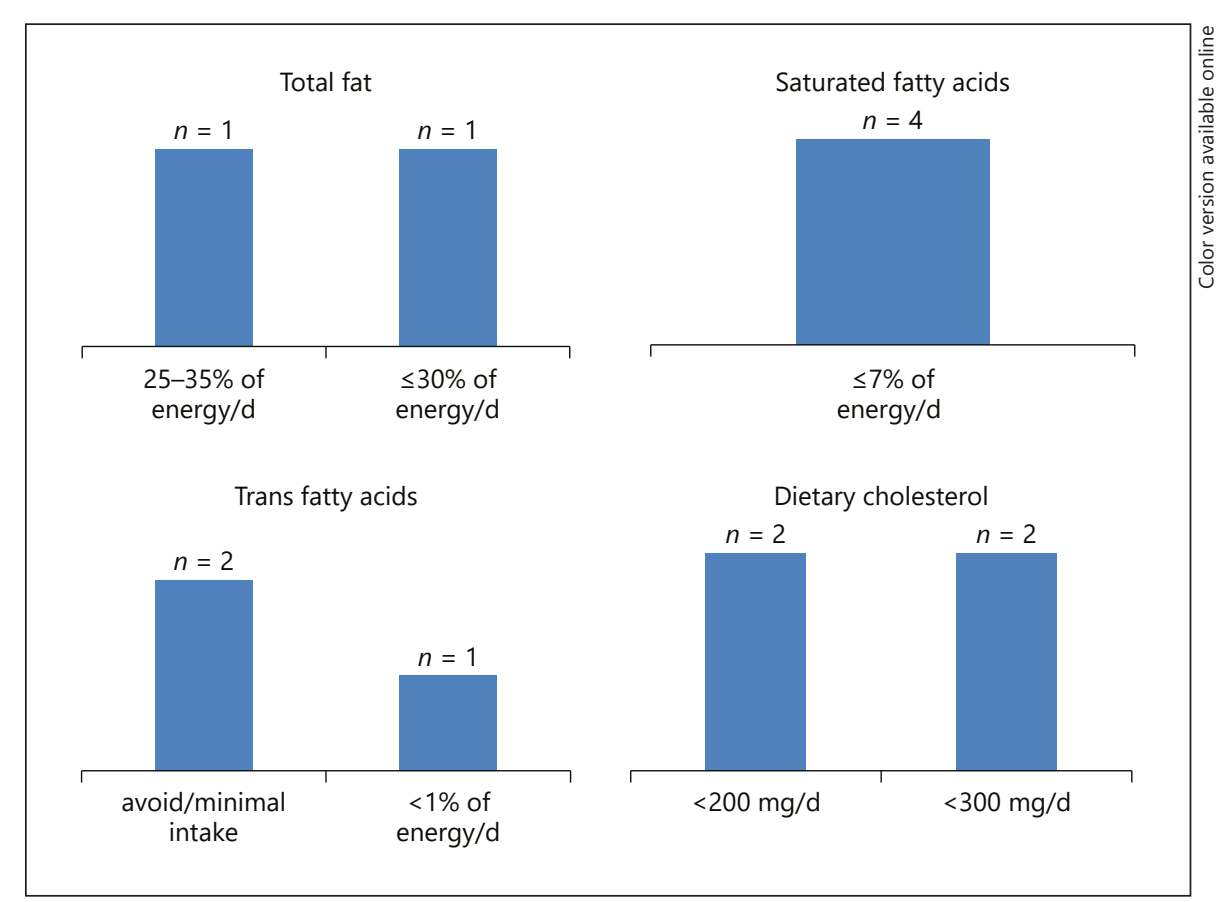

\section{Recommendations for Total Fat Intake}

Overall, 11 guidelines specified a quantitative recommendation for total fat intake, which ranged between 20 and $35 \%$ of TEI $[12,15,16,18,20-22,24,25,28,29]$. Four of those gave a recommendation for total fat intake of $30-\leq 35 \%$ of TEI $[3,15,28,29]$. In the presence of dyslipidemia, 1 organization recommended $25-35 \%$ of TEI [22], whereas another organization recommended $<30 \%$ of TEI [21]. Three organizations graded the strength of recommendation (used interchangeably with the term "certainty of evidence" by several specified a quantitative recommendation for total fat intake, which ranged between 20 and $35 \%$ of TEI $[12,15,16,18,20-22,24,25,28$, 29]. Four of those gave a recommendation for total fat intake of $30-\leq 35 \%$ of TEI organizations) which varied between "no evidence (level 4)" and "adequate/moderate" [12, 22, 29].

\section{Recommendations for MUFA Intake}

Overall, 4 guideline organizations specified a quantitative recommendation for MUFA intake, which ranged between 10 and $25 \%$ of TEI, with no strength of recommendation judgments available $[14,18,20,28]$. One guideline organization combined the recommendation for PUFA and MUFA intake (10-20\% of TEI) and judged the strength of recommendation as "no evidence (level 4)" [22].

Scoping Review of Dietary Guidelines
Recommendations for Polyunsaturated Fat Intake

Overall, 6 guideline organizations specified a quantitative recommendation for PUFA intake, which ranged between 5 and $11 \%$ of TEI, with no strength of recommendations judgments available $[15,16,18,20,25,28]$.

\section{Recommendations for Saturated Fat Intake}

Overall, 16 guideline organizations specified a quantitative range for SFA intake of $\leq 7$ to $\leq 11 \%$ of TEI (overall 17 quantitative recommendations) $[3,12,13,15,16,18$ $22,25-30]$. One guideline organization combined the recommendation for SFA and TFA intake ( $\leq 10 \%$ of TEI) [17]. In the presence of dyslipidemia, 4 organizations recommended $\leq 7 \%$ of TEI $[13,21,22,27]$, and 1 organization recommended $\leq 7 \%$ of TEI for the general population [12]. Ten organizations recommended $\leq 10 \%$ of TEI for the general population $[3,12,16,18,19,25,26,28-30]$. Three organizations specified that SFA should be replaced with MUFA and PUFA [14, 15, 26]. The strength of recommendation was graded by 8 organizations $[6,12$, $13,19,22,26,27,29]$. Limiting SFA intake was judged as "no evidence (level 4)," "moderate (Class IIa)," or "strong (e.g., GRADE A)," whereas the recommendation "strong" was most frequently used. The strength of recommendation for replacing SFA with PUFA was judged as strong by the WHO (draft guideline) if the SFA intake is greater than $10 \%$ of TEI [26]. 
Recommendations for Trans-Fat Intake

Overall, 13 guideline organizations specified a recommendation for industrial TFA intake, which ranged between complete avoidance to $\leq 2 \%$ of TEI $[3,13-16,19$, $22,24-27,29,30]$. In the presence of dyslipidemia, 3 organizations recommended complete avoidance or $\leq 1 \%$ of TEI $[13,22,27]$. The strength of recommendation was judged as "no evidence (level 4)," "moderate," or "strong" (e.g., GRADE A, Class I), whereas the recommendation "strong" was most frequently used.

\section{Recommendations for Omega-6 FA Intake}

Overall, 2 guideline organizations specified a quantitative recommendation for omega- $6 \mathrm{FA}$ intake in the range of $2.5-10 \%$ of TEI, with no strength of recommendation judgment available $[14,16]$. One guideline organization specified a quantitative recommendation for LA intake of $\geq 1 \%$ of TEI. The certainty of evidence was judged as "adequate or moderate" [29].

\section{Recommendations for Omega-3 FA Intake}

Two guideline organizations specified a quantitative recommendation for long-chain omega-3 FA intake, which ranged between 200 and $450 \mathrm{mg} / \mathrm{d}$, with a strength of recommendation judgment of "GRADE C" or " $1 \mathrm{~B}$ " $[23,29]$. One guideline organization specified a quantitative recommendation for omega-3 FA intake of $0.5-2 \%$ of TEI [16]. Two guideline organizations specified a quantitative recommendation for ALA intake, ranging between 0.2 and $1.2 \%$ of TEI (GRADE A or "moderate" certainty of evidence) $[13,29]$.

\section{Recommendations for Dietary Cholesterol Intake}

Overall, 6 guideline organizations specified a quantitative threshold for dietary cholesterol intake, which ranged between $<200$ and $<300 \mathrm{mg} / \mathrm{d}[13,16,21,22,27,28]$. Quantitative dietary cholesterol intake recommendations were given mainly for patient-centered management of dyslipidemia or other metabolic disorders $(n=4 ; 67 \%), 2$ recommending $<200 \mathrm{mg} / \mathrm{d}[13,22]$ and $2<300 \mathrm{mg} / \mathrm{d}$ [21, 27]. The strength of recommendation was judged as "no evidence (level 4)," or "moderate" (e.g., GRADE B, Class IIa). In the 2015-2020 edition of the DGA, the recommendation to limit the consumption of dietary cholesterol to $300 \mathrm{mg} / \mathrm{d}$ was withdrawn, on the basis of contemporary intake levels, it was no longer a nutrient of public health concern [3].

\section{Discussion}

\section{Summary of Findings}

This scoping review is the first to explore the available guidelines on quantity and quality of dietary fat intake and to summarize their recommendations. Overall, $20 \mathrm{di}-$ etary guidelines fulfilling our criteria published between 2015 and 2020 were identified. The guidelines identified in our scoping review often recommend total fat intake for the general population of 30 to $\leq 35 \%$ of TEI. The DGA scientific advisory committee neither listed total fat as a nutrient of concern, nor proposed any limitation to its consumption, and stated that reducing total fat or replacing it with carbohydrates has no effect on lowering CVD risk [31]. Their recommendation to limit intake of SFA to $<10 \%$ of TEI is consistent with other guidelines to keep total fat intake within the acceptable macronutrient distribution range (AMDR) of $20-35 \%$ of TEI [3]. Only a few organizations give quantitative recommendations for MUFA or PUFA intake, which ranged between 10 and $25 \%$ of TEI for MUFA and between 5 and $11 \%$ of TEI for PUFA. The highest recommendation for MUFA intake is given by the Spanish Federation of Food, Nutrition and Dietetics with $20-25 \%$ of TEI, which is driven by their recommendation to consume mainly olive oil [14]. Most guideline organizations specify a quantitative range for SFA intake, between $\leq 7$ and $\leq 11 \%$ of TEI, and further recommend replacement of SFA with MUFA and/or PUFA. For patients with metabolic disorders, a lower SFA intake threshold is recommended ( $\leq 7 \%$ of TEI). Most organizations recommend complete avoidance of industrial TFA or limit intake to $\leq 2 \%$ of TEI. Dietary cholesterol intake recommendations are now more often left out, but lower intakes $(<300 \mathrm{mg} / \mathrm{d})$ are still recommended for patients with metabolic disorders. A few organizations make recommendations for omega- 6 , and longchain omega-3 FA.

\section{Guideline Methodology and Strength of \\ Recommendations}

Identified guidelines included national dietary guidelines, clinical practice guideline, often with a focus on the general population and primary prevention of CVD, but also a few with a focus on management of metabolic disorders. Only about $50 \%$ of the guidelines conducted a systematic search for relevant studies and 35\% reported statements regarding conflict of interest of panel members.

The methodological approaches of the included guidelines varied strongly. Several organizations, such as the
Ann Nutr Metab 2021;77:65-82 DOI: $10.1159 / 000515671$
Schwingshackl et al. 
European Society of Cardiology, used their own system to grade the strength of recommendations, also referred to as "certainty of evidence," and several organizations omitted the strength of recommendations. Only the WHO draft guidelines applied the Grading of Recommendations Assessment, Development and Evaluation (GRADE) approach and graded the following recommendation as "strong": To reduce SFA to below $10 \%$, and TFA to below $1 \%$ and replace both with PUFA if SFA intake is greater than $10 \%$ of TEI. Similarly, the DGA 2015 2010 suggests reducing SFA intake to $<10 \%$ of TEI and to avoid TFA, based on strong evidence.

Moreover, the GRADE terms "certainty of evidence" and "strength of recommendation" were used interchangeably by most organizations. As suggested by the GRADE approach, distinguishing between "certainty of the evidence rating" and "grading strength of recommendation and decision" will bring clarity to the nutritional field [32-35].

\section{Comparison with Findings from Systematic Reviews}

A meta-analysis examined the evidence base of dietary fat guidelines introduced in 1977 and 1983, recommending $\leq 30 \%$ total fat of TEI. Findings from RCTs published prior to the introduction of these guidelines, showed no effect in all-cause mortality or CHD mortality when comparing different dietary fat interventions [36]. Moreover, epidemiological studies to date observed no association between CHD mortality and total fat intake and thus fail to support the dietary fat guidelines lowering total fat intake to $\leq 30 \%$ of TEI [37]. A Cochrane Review of RCTs, in which participants were randomized to a lower fat (LF) versus usual or moderate fat intake with no intention to reduce weight, showed a weight reduction effect in the LF intake group [38]. In SRs of RCTs, meta-analyses found that LF diet $(<30 \%$ dietary fat of TEI; and higher in carbohydrates) improves LDL-cholesterol and total cholesterol compared to lower carbohydrate/higher fat (presumably higher in SFA) diets, whereas a lower carbohydrate/higher fat diet performed better for HDLcholesterol and TG [38-43]. In this regard in a SR of RCTs was shown that isocaloric replacement (by $1 \%$ of TEI) of carbohydrates by SFA raises TC, LDL-C, HDL-C and reduces TG, whereas replacement of carbohydrates by MUFA and PUFA reduces TC, LDC, and TG and increases HDL-C [44].

A meta-analysis comparing the top versus bottom third of MUFA intake category found no association with all-cause mortality and CVD [45]. However, the largely different associations of MUFA from plant origin and
MUFA from animal origin with CHD risk indicate that plant-based foods are the preferable sources of MUFAs for CHD prevention [46].

A meta-analysis of 8 RCTs provided evidence that consuming PUFA instead of SFA lowers the risk of CHD [47]. Moreover, isocaloric substitution (by $1 \%$ of TEI) of SFA by MUFA and PUFA was effective to reduce LDLcholesterol [44]. The pooling project included eleven American and European cohort studies and showed that a 5\% lower energy intake from SFAs and a concomitant higher energy intake from PUFAs was inversely associated with risk of CHD [48]. On the contrary, a meta-regression of RCTs showed that higher intakes of PUFA in replacement of SFA was not associated with risk reduction in the secondary prevention of CHD [49]. Moreover, a meta-analysis of 12 prospective cohort studies found that higher SFA intakes were not associated with all-cause mortality, CVD, CHD, ischemic stroke, or T2D [50]. Total TFA intake was associated with increased risk of allcause mortality, and CHD. However, the intake of ruminant TFA was not related to all-cause mortality and CHD, but inversely associated with risk of T2D [50]. Results from the above mentioned meta-analyses and other SRs [51] indicate that the identified guidelines were not always in line with current evidence, for which reason it may be assumed that quantitative thresholds for dietary fat intake are often subjective, and a continued limited on these fats is not always justified [52]. Dietary guidelines inform consumers on adequate nutrition (i.e., energy density) and health promotion and aim to reduce the burden of noncommunicable diseases in a population by modifying dietary intake. They also guide optimal nutrient and energy supply (i.e., fat-soluble vitamins) in the context of dietary and cultural differences between countries $[53,54]$.

\section{Strengths and Limitations}

This scoping review has several strengths. First, the inclusion criteria and the search strategy were broad, including an extensive search of gray literature, such as databases of the FAO, the WHO, the World Cancer Research Fund International, the CDC, and the American Heart Association. Second, we investigated a variety of dietary fats, including total fat, MUFA, PUFA, SFA, TFA, omega-3, and omega-6 FA. Third, we described the different methodological approaches (i.e., systematic search for relevant studies, multidisciplinary panel, reporting conflict of interest of panel members, description of recommendation categorization) used by the dietary guidelines. Fourth, we summarized the strength of recommen- 
dations grade/certainty of evidence rating for dietary fat and fat quality for each included guideline.

Limitations need to be considered as well. First, guidelines were only included if at least 1 quantitative recommendation was provided for either total fat, MUFA, PUFA, SFA, TFA, omega-3 or omega-6 FA. Second, guidelines focusing on chronic diseases such as dementia, chronic kidney disease, and respiratory diseases amongst others were not considered. Third, we did not cover the full spectrum of possible dietary fat intake since we excluded food based dietary guidelines without at least 1 quantitative recommendation for any of the followings: total fat, MUFA, PUFA, SFA, TFA, omega-3, or omega-6 FA. Focusing on foods rather than nutrients has been suggested recently also by Astrup and colleagues [55]. SRs of prospective cohort studies has shown mainly no detrimental association between SFA-rich foods such as dairy or chocolate and risk of chronic diseases [56-62]. To improve the trustworthiness of such food-disease associations, the use of novel statistical methods (e.g., substitution analyses or network meta-analyses) is highly recommended [63, 64].

\section{Conclusion}

Although the methodological approaches of the dietary guidelines were heterogeneous, most of them recommend total fat intake of 30 to $\leq 35 \%$ of TEI, replacement of SFA with PUFA and MUFA, and avoidance of industrial TFA. To improve the trustworthiness of future guidelines on dietary fat intake and fat quality, transparent approaches to evaluate the certainty of the evidence supporting their recommendations are necessary.

\section{Acknowledgements}

We are grateful to the members of the IUNS task force on dietary fat quality (Prof. Tom Brenna, Prof. Irina Kovalskys, Prof. Alice Lichtenstein, Prof. Ronald Mensink, Prof. Ladda Mo-Suwan, Prof. Marius Smuts, Prof. Shoichiro Tsugane, and Prof. Yang Yuexin) for their critical review of the manuscript and insightful comments.

\section{Conflict of Interest Statement}

L.S.: is a member of the GRADE working group; J.Z.: no conflict of interest; J.B.: no conflict of interest; S.S.W.: no conflict of interest; B.N.: is a member of the GRADE working group; H.H.: no conflict of interest; B.K.: no conflict of interest; J.J.M.: is a member of the WHO Nutrition Guidance Expert Advisory Group; Director, Freiburg GRADE Center.

\section{Funding Sources}

The study was funded by the International Union of Nutritional Sciences.

\section{Author Contributions}

L.S., J.Z., J.B., S.S.W., B.N., H.H., B.K., and J.J.M. designed the research. L.S., J.Z., and J.B. analyzed the data and wrote the first draft of the paper. L.S., J.Z., J.B., S.S.W., B.N., H.H., B.K., and J.J.M. interpreted the data, read the manuscript, and approved the final version. L.S. and J.J.M. are guarantors.

\section{References}

1 Forouhi NG, Krauss RM, Taubes G, Willett W. Dietary fat and cardiometabolic health: evidence, controversies, and consensus for guidance. BMJ. 2018 Jun 13;361:k2139.

2 Kannel WB, Castelli WP, Gordon T, McNamara PM. Serum cholesterol, lipoproteins, and the risk of coronary heart disease. The Framingham study. Ann Intern Med. 1971 Jan;74(1):1-12.

3 U.S. Department of Health and Human Services and U.S. Department of Agriculture. 2015-2020 Dietary Guidelines for Americans. 8th ed.; 2015 Dec. Available from: http:// health.gov/dietaryguidelines/2015/guidelines/ Accessed 2020 Feb 12.
4 U.S. Department of Health and Human Services. Nutrition and your Health. Dietary Guidelines for Americans. United States; 1980. Available from: https://health.gov/ourwork/food-nutrition/previous-dietaryguidelines/1980 Accessed 2020 Feb 12.

5 Jahns L, Davis-Shaw W, Lichtenstein AH, Murphy SP, Conrad Z, Nielsen F. The history and future of dietary guidance in America. Adv Nutr. 2018;9(2):136-47.

6 U.S. Department of Health and Human Services and U.S. Department of Agriculture. Dietary Guidelines for Americans, 2005. 6th ed. Washington, DC: U.S. Government Printing Office; 2005 Jan. Available from: https://health.gov/ our-work/food-nutrition/previous-dietaryguidelines/2005 Accessed $2020 \mathrm{Feb} 12$.

7 Teicholz N. The scientific report guiding the US dietary guidelines: is it scientific? BMJ. 2015;351:h4962.
8 GBD 2016 Causes of Death Collaborators. Global, regional, and national age-sex specific mortality for 264 causes of death, 1980-2016: a systematic analysis for the Global Burden of Disease Study 2016. Lancet. 2017 Sep 16; 390(10100):1151-210.

9 GBD 2017 Diet Collaborators. Health effects of dietary risks in 195 countries, 1990-2017: a systematic analysis for the Global Burden of Disease Study 2017. Lancet. 2019 May 11; 393(10184):1958-72.

10 Peters MDJ, Godfrey C, McInerney P, Baldini Soares C, Khalil H, Parker D. Chapter 11: Scoping Reviews. In: Aromataris E, Munn Z, editors. Joanna Briggs Institute Reviewer's Manual. The Joanna Briggs Institute; 2017. Available from: https://wiki.jbi.global/display/MANUAL Accessed 2020 Oct 21. 
11 Tricco AC, Lillie E, Zarin W, O'Brien KK, Colquhoun $\mathrm{H}$, Levac D, et al. PRISMA extension for scoping reviews (PRISMA-ScR): checklist and explanation. Ann Intern Med. 2018 Oct 2;169(7):467-73.

12 Dietary Reference Intakes for Japanese (2020) (Ministry of Health, Labour and Welfare, 2019).

13 Jacobson TA, Maki KC, Orringer CE, Jones PH, Kris-Etherton P, Sikand G, et al. National lipid association recommendations for patient-centered management of Dyslipidemia: Part 2. J Clin Lipidol. 2015 Nov-Dec;9(6 Suppl):S1-122.e1.

14 Ros E, López-Miranda J, Picó C, Rubio MÁ, Babio N, Sala-Vila A, et al. [Consensus on fats and oils in the diet of S Ish Adults; Position Paper of the Spanish Federation of Food, Nutrition and Dietetics Societies]. Nutr Hosp. 2015;32(2):435-77.

15 Wolfram G, Bechthold a, Boeing H, Ellinger S, Hauner H, Kroke a, et al. Evidence-based guideline of the German Nutrition Society: fat intake and prevention of selected nutritionrelated diseases. Ann Nutr Metab. 2015;67(3): 141-204.

16 Ministerio de Salud, Argentina. Guías alimentarias para la población Argentina. 2015. Available from: http://www.msal.gob.ar/ima ges/stories/bes/graficos/ 0000000817cnt-2016-04_Guia_Alimentaria_ completa_web.pdf Accessed $2020 \mathrm{Feb} 11$.

17 Ministry of Health, New Zealand. Eating and activity guidelines. 2015. Available from: https://www.health.govt.nz/our-work/eatingand-activity-guidelines Accessed 2020 Feb 11.

18 Instituto Colombiano de Bienestar Familiar, Colombia. Guías Alimentarias. Basadas en Alimentos para la población Colombiana mayor de 2 anos. 2015. Available from: www. icbf.gov.co Accessed 2020 Feb 11.

19 Piepoli MF, Hoes AW, Agewall S, Albus C, Brotons C, Catapano AL, et al. 2016 European Guidelines on cardiovascular disease prevention in clinical practice: The Sixth Joint Task Force of the European Society of Cardiology and Other Societies on Cardiovascular Disease Prevention in Clinical Practice (constituted by representatives of 10 societies and by invited experts)Developed with the special contribution of the European Association for Cardiovascular Prevention \& Rehabilitation (EACPR). European Heart Journal. 2016; 37(29):2315-81.

20 Public Health England, United Kingdom. Government recommendations for energy and nutrients for males and females aged $1-18$ years and 19+ years. 2016. Available from: https:// www.google.com/url?sa=t\& $\quad r c t=j \& \quad \mathrm{q}=\&$ esrc $=s \&$ source $=$ web \&cd $=1$ \&ved $=2$ ahUKEwjP i7LT1cnnAhVk5KYKHUOqBDsQFjAAegQIARAB\& url=https\%3A\%2F\%2Fassets.publishing.service.gov.uk\%2Fgovernment\%2Fupload s\%2Fsystem\%2Fuploads\%2Fattachment_data \%2Ffile\%2F618167\%2Fgovernment_dietary_ recommendations.pdf\& usg $=\mathrm{AOvVaw} 3 \mathrm{CVEG}$ 0j0CygaQHIKfjdAUO Accessed 2020 Feb 11.
21 National Institute for Health and Care Excellence. NICE Guidance: Cardiovascular disease: risk assessment and reduction, including lipid modification. 2016. Available from: https://www.nice.org.uk/guidance/cg181 Accessed 2020 Feb 11.

22 Jellinger PS, Handelsman Y, Rosenblit PD, Bloomgarden ZT, Fonseca VA, Garber AJ, et al. American Association of Clinical Endocrinologists and American College of Endocrinology Guidelines for Management of Dyslipidemia and Prevention of Cardiovascular Disease. Endocr Pract. 2017 Apr;23(Suppl 2): $1-87$.

23 Sanchez-Borrego R, von Schacky C, Osorio MJA, Llaneza P, Pinto X, Losa F, et al. Recommendations of the Spanish Menopause Society on the consumption of omega-3 polyunsaturated fatty acids by postmenopausal women. Maturitas. 2017;103:71-7.

24 National Guidelines for Healthy Diets and Physical Activity 2017. Kenya: Ministry of Health. 2017. Available from: https://www. nutritionhealth.or.ke/programmes/healthydiets-physical/ Accessed 2020 Feb 11.

25 Guías Alimentarias des Ecuador. Eduador: Government of the Republic of Ecuador. 2018. Available from: http://www.fao.org/nutrition/education/food-dietary-guidelines/ regions/countries/ecuador/en/ Accessed $2020 \mathrm{Feb} 13$.

26 World Health Organization. Draft guidelines on saturated fatty acid and trans-fatty acid intake for adults and children. 2018. Available from: https://extranet.who.int/dataform/upload/surveys/666752/files/Draft $\% 20$ W H O \% 20 S F A - T F A \% 20 g u i d e lines $04052018 \% 20$ Public\%20Consultation(1).pdf Accessed 2020 Feb 11.

27 Mach F, Baigent C, Catapano AL, Koskinas KC, Casula M, Badimon L, et al. 2019 ESC/ EAS Guidelines for the management of dyslipidaemias: lipid modification to reduce cardiovascular risk: The Task Force for the management of dyslipidaemias of the European Society of Cardiology (ESC) and European Atherosclerosis Society (EAS). Eur Heart J. 2019;41(1):111-88.

28 Ministry of Agriculture, Food and Forestry, Italy. Linee guida para una sana alimentazione. 2019. Available from: https://www.crea. gov.it/web/alimenti-e-nutrizione/-/lineeguida-per-una-sana-alimentazione-2018 Accessed 2020 Feb 13.

29 Saturated fats and health: SACN report. The Scientific Advisory Committee on Nutrition (SACN) report on saturated fats and health. 2019. Available from: https://www.gov.uk/ government/publications/saturated-fatsand-health-sacn-report Accessed $2020 \mathrm{Feb}$ 11.

30 Health Canada, Canada. Canada's Dietary Guideline for Health Professionals and Policy Makers. 2019. Available from: http://www. canada.ca/FoodGuide Accessed 2020 Feb 11.
31 Mozaffarian D, Ludwig DS. The 2015 US dietary guidelines: lifting the ban on total dietary fat. JAMA. 2015;313(24):2421-2.

32 Alonso-Coello P, Schünemann HJ, Moberg J, Brignardello-Petersen R, Akl EA, Davoli M, et al. GRADE Evidence to Decision (EtD) frameworks: a systematic and transparent approach to making well informed healthcare choices. 1: Introduction. BMJ. 2016;353: i2016.

33 Schwingshackl L, Schünemann HJ, Meerpohl JJ. Improving the trustworthiness of findings from nutrition evidence syntheses: assessing risk of bias and rating the certainty of evidence. Eur J Nutr. 2020 Dec 30.

34 Kroke A, Schmidt A, Kalotai N, Amini A, M, Lehmann A, et al. Dietary protein intake and health-related outcomes: a methodological approach for the evidence-based guideline of the German nutrition society.

35 Werner SS, Binder N, Toews I, Schünemann HJ, Meerpohl JJ, Schwingshackl L. Use of the GRADE approach for rating the certainty of evidence in evidence syntheses published in high impact factor nutrition journals: a methodological survey. J Clin Epidemiol. 2021;135: 54-69.

36 Harcombe Z, Baker JS, Cooper SM, Davies B, Sculthorpe N, DiNicolantonio JJ, et al. Evidence from randomised controlled trials did not support the introduction of dietary fat guidelines in 1977 and 1983: a systematic review and meta-analysis. Open Heart. 2015; 2(1):e000196.

37 Harcombe Z, Baker JS, Davies B. Evidence from prospective cohort studies does not support current dietary fat guidelines: a systematic review and meta-analysis. Br J Sports Med. 2017 Dec;51(24):1743-9.

38 Hooper L, Abdelhamid A, Bunn D, Brown T, Summerbell CD, Skeaff CM. Effects of total fat intake on body weight. Cochrane Database Syst Rev. 2015 Aug 7(8):Cd011834.

39 Schwingshackl L, Hoffmann G. Comparison of effects of long-term low-fat vs high-fat diets on blood lipid levels in overweight or obese patients: a systematic review and meta-analysis. J Acad Nutr Diet. 2013 Dec;113(12):1640 61.

40 Sackner-Bernstein J, Kanter D, Kaul S. Dietary intervention for overweight and obese adults: comparison of low-carbohydrate and low-fat diets. A meta-analysis. PLoS One. 2015;10(10):e0139817.

41 Mansoor N, Vinknes KJ, Veierød MB, Retterstøl K. Effects of low-carbohydrate diets v. low-fat diets on body weight and cardiovascular risk factors: a meta-analysis of randomised controlled trials. Br J Nutr. 2016 Feb 14; 115(3):466-79.

$42 \mathrm{Lu} \mathrm{M}$, Wan Y, Yang B, Huggins CE, Li D. Effects of low-fat compared with high-fat diet on cardiometabolic indicators in people with overweight and obesity without overt metabolic disturbance: a systematic review and meta-analysis of randomised controlled trials. Br J Nutr. 2018 Jan;119(1):96-108. 
43 Gjuladin-Hellon T, Davies IG, Penson P, Amiri Baghbadorani R. Effects of carbohydrate-restricted diets on low-density lipoprotein cholesterol levels in overweight and obese adults: a systematic review and meta-analysis. Nutr Rev. 2019 Mar 1;77(3):161-80.

44 Mensink R. Effects of saturated fatty acids on serum lipids and lipoproteins: a systematic review and regression analysis. Geneva: World Health Organization; 2016.

45 Schwingshackl L, Hoffmann G. Monounsaturated fatty acids, olive oil and health status: a systematic review and meta-analysis of cohort studies. Lipids Health Dis. 2014 Oct 1;13:154.

46 Zong G, Li Y, Sampson L, Dougherty LW, Willett WC, Wanders AJ, et al. Monounsaturated fats from plant and animal sources in relation to risk of coronary heart disease among US men and women. Am J Clin Nutr. 2018 Mar 1;107(3):445-53.

47 Mozaffarian D, Micha R, Wallace S. Effects on coronary heart disease of increasing polyunsaturated fat in place of saturated fat: a systematic review and meta-analysis of randomized controlled trials. PLoS Med. 2010 Mar 23; 7(3):e1000252.

48 Jakobsen MU, O'Reilly EJ, Heitmann BL, Pereira MA, Bälter K, Fraser GE, et al. Major types of dietary fat and risk of coronary heart disease: a pooled analysis of 11 cohort studies. Am J Clin Nutr. 2009 May;89(5):1425-32.

49 Schwingshackl L, Hoffmann G. Dietary fatty acids in the secondary prevention of coronary heart disease: a systematic review, meta-analysis and meta-regression. BMJ Open. 2014; 4(4):e004487.

50 de Souza RJ, Mente A, Maroleanu A, Cozma AI, Ha V, Kishibe T, et al. Intake of saturated and trans unsaturated fatty acids and risk of all cause mortality, cardiovascular disease, and type 2 diabetes: systematic review and meta-analysis of observational studies. BMJ. 2015 Aug 11;351:h3978.

51 Schwingshackl L, Zähringer J, Beyerbach J, Werner SW, Heseker H, Koletzko B, et al. Total dietary fat intake, fat quality and health outcomes: a scoping review of systematic reviews of prospective studies. Ann Nutr Metab. 2021 Mar;31:1-12.

52 Demasi M. US nutritionists call for dietary guideline limits on saturated fat intake to be lifted. BMJ. 2020;371:m4226.

53 Bechthold A, Boeing H, Tetens I, Schwingshackl L, Nöthlings U. Perspective: foodbased dietary guidelines in Europe-Scientific Concepts, Current Status, and Perspectives. Adv Nutr. 2018 Sep 1;9(5):544-60.

54 Schwingshackl L, Watzl B, Meerpohl JJ. The healthiness and sustainability of food based dietary guidelines. BMJ. 2020;370:m2417.

55 Astrup A, Magkos F, Bier DM, Brenna JT, de Oliveira Otto MC, Hill JO, et al. Saturated fats and health: a reassessment and proposal for food-based recommendations: JACC Stateof-the-Art Review. J Am Coll Cardiol. 2020 Aug 18;76(7):844-57.

56 Schwingshackl L, Hoffmann G, Lampousi AM, Knüppel S, Iqbal K, Schwedhelm C, et al. Food groups and risk of type 2 diabetes mellitus: a systematic review and meta-analysis of prospective studies. Eur J Epidemiol. 2017 May;32(5):363-75.

57 Schwingshackl L, Schwedhelm C, Hoffmann G, Knüppel S, Iqbal K, Andriolo V, et al. Food groups and risk of hypertension: a systematic review and dose-response meta-analysis of prospective studies. Adv Nutr. 2017 Nov;8(6): 793-803.
58 Schwingshackl L, Schwedhelm C, Hoffmann G, Knüppel S, Laure Preterre A, Iqbal K, et al. Food groups and risk of colorectal cancer. Int J Cancer. 2018 May 1;142(9):1748-58.

59 Bechthold A, Boeing H, Schwedhelm C, Hoffmann G, Knüppel S, Iqbal K, et al. Food groups and risk of coronary heart disease, stroke and heart failure: A systematic review and dose-response meta-analysis of prospective studies. Crit Rev Food Sci Nutr. 2019; 59(7):1071-90.

60 Schlesinger S, Neuenschwander M, Schwedhelm C, Hoffmann G, Bechthold A, Boeing $\mathrm{H}$, et al. Food groups and risk of overweight, obesity, and weight gain: a systematic review and dose-response meta-analysis of prospective studies. Adv Nutr. 2019 Mar 1;10(2): 205-18

61 Schwingshackl L, Knüppel S, Michels N, Schwedhelm C, Hoffmann G, Iqbal K, et al. Intake of 12 food groups and disability-adjusted life years from coronary heart disease, stroke, type 2 diabetes, and colorectal cancer in 16 European countries. Eur J Epidemiol. 2019 Aug;34(8):765-75.

62 Morze J, Schwedhelm C, Bencic A, Hoffmann G, Boeing H, Przybylowicz K, et al. Chocolate and risk of chronic disease: a systematic review and dose-response meta-analysis. Eur J Nutr. 2020 Feb;59(1):389-97.

63 Song M, Giovannucci E. Substitution analysis in nutritional epidemiology: proceed with caution. Eur J Epidemiol. 2018 2018/02/01; 33(2):137-40.

64 Schwingshackl L, Schwarzer G, Rücker G, Meerpohl JJ. Perspective: network meta-analysis reaches nutrition research: current status, scientific concepts, and future directions. Adv Nutr. 2019 Sep 1;10(5):739-54. 